\title{
Angiotensin-(1-7) in Paraventricular Nucleus Contributes to the Enhanced Cardiac Sympathetic Afferent Reflex and Sympathetic Activity in Chronic Heart Failure Rats
}

\author{
Xingsheng Ren ${ }^{\mathrm{a}} \quad$ Feng Zhang ${ }^{\mathrm{a}} \quad$ Mingxia Zhao $^{\mathrm{a}}$ Zhenzhen Zhao ${ }^{\mathrm{a}, \mathrm{b}}$ Shuo Sun ${ }^{\mathrm{a}}$ \\ Dustin R Fraidenburg c,d Haiyang Tang ${ }^{c}$ Ying Han ${ }^{\mathrm{a}}$
}

aKey Laboratory of Cardiovascular Disease and Molecular Intervention, Department of Physiology, Nanjing Medical University, Nanjing, Jiangsu, China, 'bThe first clinical medical college, Nanjing Medical University, Nanjing, Jiangsu, China; 'Division of Translational and Regenerative Medicine, Department of Medicine, University of Arizona, Tucson, Arizona, USA, dDepartment of Medicine, University of Illinois at Chicago, Chicago, Illinois, USA

\section{Key Words}

Chronic heart failure - Angiotensin-(1-7) - Paraventricular nucleus - Cardiac sympathetic afferent reflex $\cdot N A D(P) H$ oxidase-derived superoxide anions $•$ CAMP-PKA signaling pathway

\begin{abstract}
Background/Aims: Cardiac sympathetic afferent reflex (CSAR) enhancement contributes to exaggerated sympathetic activation in chronic heart failure (CHF). The current study aimed to investigate the roles of angiotensin (Ang)-(1-7) in CSAR modulation and sympathetic activation and Ang-(1-7) signaling pathway in paraventricular nucleus of CHF rats. Methods: CHF was induced by coronary artery ligation. Responses of renal sympathetic nerve activity (RSNA) and mean arterial pressure (MAP) to epicardial application of capsaicin were used to evaluate CSAR in rats with anesthesia. Results: Ang-(1-7) increased RSNA, MAP, CSAR activity, cAMP level, $\mathrm{NAD}(\mathrm{P}) \mathrm{H}$ oxidase activity and superoxide anion level more significantly in $\mathrm{CHF}$ than in shamoperated rats, while Mas receptor antagonist A-779 had the opposite effects. Moreover, Ang(1-7) augmented effects of Ang II in CHF rats. The effects of Ang-(1-7) were blocked by A-779, adenylyl cyclase inhibitor SQ22536, protein kinase A inhibitor Rp-cAMP, superoxide anion scavenger tempol and $\mathrm{NAD}(\mathrm{P}) \mathrm{H}$ oxidase inhibitor apocynin. Mas and $A \mathrm{~T}_{1}$ receptor protein expressions, Ang-(1-7) and Ang II levels in CHF increased. Conclusions: These results indicate that Ang-(1-7) in paraventricular nucleus enhances CSAR and sympathetic output not only by exerting its own effects but also by augmenting the effects of Ang II through Mas receptor in CHF. Endogenous Ang-(1-7)/Mas receptor activity contributes to CSAR enhancement and sympathetic activation in $\mathrm{CHF}$, and $\mathrm{NAD}(\mathrm{P}) \mathrm{H}$ oxidase-derived superoxide anions and the CAMP-PKA signaling pathway are involved in mediating the effects of Ang-(1-7) in CHF.




\section{Cellular Physiology Cell Physiol Biochem 2017;42:2523-2539 \\ \begin{tabular}{l|l|l} 
and Biochemistry Published onlıne: August 23, 2017 & $\begin{array}{l}\text { (c) } 2017 \text { The Author(s). Published by S. Karger AG, Basel } \\
\text { www.karger.com/cpb }\end{array}$
\end{tabular} \\ Ren et al.: Ang-(1-7) in Chronic Heart Failure}

\section{Introduction}

Chronic heart failure (CHF) is a serious debilitating condition characterized by poor survival rates and an increasing level of prevalence. Exaggerated sympatho-excitation, a hallmark of CHF, contributes to arrhythmias [1], further hemodynamic deterioration and multiorgan damage and is a critical factor in the development and progression of the CHF state. The degree of sympatho-excitation is predictive of the likelihood of survival in CHF $[2,3]$. The cardiac sympathetic afferent reflex (CSAR), a sympatho-excitatory reflex, can be induced by stimulating cardiac sympathetic afferents with exogenous chemicals or endogenous chemicals from the myocardium during myocardial ischemia in CHF $[4,5]$. The CSAR is enhanced in CHF, and this enhancement at least partially contributes to increases in sympathetic outflow in the disease [6, 7]. Thus, CSAR suppression and, ultimately, sympathoexcitation inhibition may be good strategies for treating patients with CHF $[2,8]$.

The paraventricular nucleus (PVN) is an integrative site involved in regulating sympathetic outflow and cardiovascular activity [9] and is a component of the central neurocircuitry of the CSAR [10]. Angiotensin (Ang)-(1-7) is accepted as an important biologically active peptide in the renin-angiotensin system (RAS) family that adjusts sympathetic outflow and cardiovascular activity. Most of its effects are mediated by the Mas receptor [11,12], which is abundantly expressed in the PVN $[13,14]$ and is selectively blocked by its specific antagonist, D-Alanine-Ang-(1-7) (A-779) [15, 16]. Our recent studies have shown that microinjection of Ang-(1-7) into either the PVN or the rostral ventrolateral medulla (RVLM), another important site for regulating sympathetic outflow, enhances the CSAR and increases arterial blood pressure and sympathetic activity in renovascular hypertensive rats [17-20]. These findings underline the important roles of Ang-(1-7) in the PVN or RVLM in modulating blood pressure, sympathetic activity and the CSAR in hypertension. However, it is not yet known whether Ang-(1-7) in the PVN contributes to CSAR enhancement and excessive sympathetic activation in CHF.

Previous studies have demonstrated that Ang-(1-7) inhibits vascular growth via prostacyclin-mediated cAMP production and protein kinase A (PKA) activation [21] and that inhibition of either adenylyl cyclase (AC) or PKA activity attenuates Ang-(1-7)-induced ERK1/2 activation in glomerular mesangial cells [22]. Our previous study also showed that the cAMP-PKA pathway participates in Ang-(1-7)-mediated effects in the RVLM [18] or PVN [17] in renovascular hypertension. In addition, superoxide anions scavengers have been shown to abolish both the effects of Ang II in the PVN [23, 24] and the effects of Ang-(1-7) in the RVLM [25] on arterial blood pressure, sympathetic activity and CSAR in rats. However, whether the cAMP-PKA pathway and/or reactive oxygen species (ROS) are involved in mediating the effects of Ang-(1-7) in the PVN in CHF rats remains unclear. Thus, the present study was designed to determine whether Ang-(1-7) in the PVN contributes to the CSAR enhancement and sympathetic activation that occur in CHF, to elucidate its interactions with Ang II, and to determine whether the cAMP-PKA pathway and NAD(P)H oxidase-derived superoxide anions are involved in the effects of Ang-(1-7) on the CSAR and sympathetic outflow in CHF rats.

\section{Materials and Methods}

The experiments for this study were conducted using male Sprague-Dawley rats. The procedures were approved by the Nanjing Medical University Experimental Animal Care and Use Committee and complied with the Guide for the Care and Use of Laboratory Animals (NIH publication No. 85-23, revised 1996). The rats were kept in a temperature-controlled room, maintained under a $12 \mathrm{~h}-12 \mathrm{~h}$ light-dark cycle and allowed free access to standard chow and tap water.

Model of CHF

CHF was induced by coronary artery ligation, as previous studies described [26-28]. Briefly, all the rats were anesthetized with sodium phenobarbital (50 mg/kg, i.p.) and handled using sterile techniques. 


\section{Cellular Physiology Cell Physiol Biochem 2017;42:2523-2539 \\ \begin{tabular}{l|l|l} 
and Biochemistry Published onlıne: August 23, 2017 & $\begin{array}{l}\text { (c) } 2017 \text { The Author(s). Published by S. Karger AG, Basel } \\
\text { www.karger.com/cpb }\end{array}$
\end{tabular} \\ Ren et al.: Ang-(1-7) in Chronic Heart Failure}

The left coronary artery was ligated with a 6-0 suture near the point at which it branches off from the aorta. Approximately $30 \%$ of the animals used in the experiments died. Death occurred mainly during the first day after ligation. The sham-operated (Sham) rats were treated the same as the CHF rats, except their coronary arteries were not ligated. A final experiment was performed at 6-8 weeks after coronary ligation or sham surgery. The criteria used to define $\mathrm{CHF}$ were as follows: an elevated left ventricular end-diastolic pressure (LVEDP) (>13 $\mathrm{mmHg}$ ) and a 40\% decrease in the maximum of the first differentiation of left ventricular pressure $\left(\mathrm{LV}+\mathrm{dp} / \mathrm{dt}_{\max }\right)$.

\section{Echocardiography measurements}

Rat transthoracic echocardiography was performed under light anesthesia $(50 \mathrm{mg} / \mathrm{kg}$ sodium pentobarbital, i.p.) using an ultrasound system (Vevo 2100, VisualSonics, Canada) and a 21-MHz probe to assess left ventricular (LV) function, as described in our previous report [18]. The LV end-diastolic diameter (LVEDD), LV end-systolic diameter (LVESD), interventricular septal thickness in diastole (IVSd), interventricular septal thickness in systole (IVSs), LV posterior wall thickness in diastole (LVPWd) and LV posterior wall thickness in systole (LVPWs) were measured, and the LV ejection fraction (EF), LV fractional shortening (FS), LV mass and LV mass/ Body weight (BW) ratio were calculated. All measurements were averaged over three consecutive cardiac cycles.

\section{General procedures of the acute experiments}

The acute experiments were performed at 6-8 weeks after coronary ligation or sham surgery. Each rat was intraperitoneally anesthetized with urethane $(800 \mathrm{mg} / \mathrm{kg})$ and $\alpha$-chloralose $(40 \mathrm{mg} / \mathrm{kg})$, and an appropriate level of anesthesia was maintained using supplemental doses of anesthetic. A rodent ventilator (model 683, Harved Apparatus Inc., USA) was used to mechanically ventilate the rats with room air. To minimize the confounding effects of the baroreflex on sympathetic activity and blood pressure, we performed and verified bilateral baroreceptor denervation and vagotomy, as previously described $[18,29]$. The right carotid artery was cannulated and connected to a pressure transducer (MLT0380, ADInstruments, Australia) to record continuous arterial blood pressure (ABP), mean arterial pressure (MAP) and heart rate (HR), and a catheter entering the left ventricle from the right carotid artery was used to record LV pressure.

\section{Renal sympathetic nerve activity (RSNA) recordings}

The left renal sympathetic nerve was isolated after a retroperitoneal incision was made. To eliminate its afferent activity, we cut the renal nerve distally. The nerve was then placed on a pair of silver electrodes and immersed in warm mineral oil. Its signals were amplified and recorded by a 4-channel AC/DC differential amplifier (DP-304, Warner Instruments, Hamden, CT, USA) with a high-pass filter set at $10 \mathrm{~Hz}$ and a lowpass filter set at 3, $000 \mathrm{~Hz}$. RSNA was integrated at a time constant of $100 \mathrm{~ms}$. At the end of each experiment, the background noise was determined after the central end of the nerve was sectioned and was subtracted from the integrated RSNA values. The raw and integrated RSNA, ABP, MAP and HR were simultaneously recorded with a PowerLab data acquisition system (8SP, ADInstruments, Australia). The change in RSNA was expressed as the percent change from the value recorded before chemical intervention.

\section{Evaluation of the CSAR}

The CSAR was evaluated as previously described [18, 29]. First, a limited left lateral thoracotomy was performed, and the pericardium was removed to expose the heart. Then, the CSAR was elicited by stimulating cardiac sympathetic afferent nerves via the epicardial application of a piece of filter paper ( 3 $\mathrm{mm} \times 3 \mathrm{~mm}$ ) containing capsaicin $(1.0 \mathrm{nmol}$ in $2.0 \mu \mathrm{l})$ to the non-infarcted area of the $\mathrm{LV}$ anterior wall. One minute later, the filter paper was removed, and the ventricular surface was rinsed 3 times with $10 \mathrm{ml}$ of normal saline $\left(37^{\circ} \mathrm{C}\right)$. The CSAR was evaluated based on the responses of RSNA and MAP to the epicardial application of capsaicin.

\section{PVN microinjection}

The rat was assembled in a stereotaxic frame (Stoelting, Chicago, USA). The stereotaxic coordinates for the PVN were $1.8 \mathrm{~mm}$ caudal from bregma, $0.4 \mathrm{~mm}$ lateral to the midline and $7.9 \mathrm{~mm}$ ventral to the dorsal surface, according to Paxinos \& Watson's rat atlas. Bilateral PVN microinjections were performed with two glass micropipettes (50- $\mu \mathrm{m}$ tip diameter), and the injection rate was controlled by a dual-channel 


\section{Cellular Physiology Cell Physiol Biochem 2017;42:2523-2539 \\ \begin{tabular}{l|l|l} 
and Biochemistry Published online: August 23, 2017 & $\begin{array}{l}\text { C) } 2017 \text { The Author(s). Published by S. Karger AG, Basel } \\
\text { www.karger.com/cpb }\end{array}$ \\
\hline
\end{tabular} \\ Ren et al.: Ang-(1-7) in Chronic Heart Failure}

microdialysis infusion syringe pump (53101V, Stoelting Co., Illinois, USA). The bilateral PVN microinjections were completed within $1 \mathrm{~min}$, and the microinjection volume was $50 \mathrm{nl}$ for each side of the PVN. At the end of the experiment, $50 \mathrm{nl}$ of Evans Blue dye (2\%) was injected into each microinjection site. The microinjection sites were subsequently histologically verified with a microscope, and the data pertaining to the microinjection sites outside the PVN were excluded from the data analysis.

\section{PVN sample preparation}

PVN tissue samples were collected and homogenized as previously reported [29]. Briefly, the brain was quickly removed from the skull of each rat and flash-frozen in liquid nitrogen before being stored at $-70{ }^{\circ} \mathrm{C}$. The brain was subsequently coronal sectioned using a cryostat microtome (CM1900, Leica LTD), and the PVN area was punched out with a 15-gauge needle. The punched tissues were then homogenized and centrifuged, and the total protein in the homogenate supernatant was extracted and measured using a protein assay kit (BCA, Pierce).

\section{Measurement of Ang II and Ang-(1-7) levels}

Both Ang-(1-7) levels and Ang II levels in the PVN tissue homogenate supernatant were determined using commercial peptide enzyme-linked immunoassay kits (USCN Life Science Inc., USA), in accordance with the manufacturer's instructions.

\section{Measurement of $A T_{1}$ receptor and Mas receptor protein expression levels}

Mas and $\mathrm{AT}_{1}$ receptor protein expression levels in the PVN were determined by western blotting, as described in previous reports $[19,20]$. Briefly, the proteins in the PVN tissue homogenate supernatant were separated by a 10\% SDS-PAGE gel and transferred to a nitrocellulose membrane, which was subsequently probed with a rabbit polyclonal antibody against the $\mathrm{AT}_{1}$ receptor (1:500; Abcam, Cambridge, MA, USA) or Mas receptor (1:200, Alomone Labs, Israel) before being incubated with horseradish peroxidase-conjugated goat anti-rabbit IgG (1:5000; Immunology Consultants Lab, Portland, OR, USA). The bands were visualized by enhanced chemiluminescence using an ECL system (Pierce Chemical, Rockford, IL, USA). GAPDH (1:5000; Bioworld Technology Inc., Louis, MN, USA) protein was used as a loading control. AT ${ }_{1}$ receptor protein and Mas receptor protein levels were normalized to those of GAPDH protein.

\section{Measurement of cAMP levels}

cAMP levels in the PVN were determined by an enzyme-linked immunoassay kit (Cayman Chemical Co, USA), according to the manufacturer's instructions $[18,30]$.

\section{Measurement of $N A D(P) H$ oxidase activity}

NAD(P)H oxidase activity in the PVN was measured by enhanced lucigenin chemiluminescence, as described in our previous reports [24, 31]. Briefly, NAD(P)H $(100 \mu \mathrm{M})$ was added to the medium as a substrate to react with $\mathrm{NAD}(\mathrm{P}) \mathrm{H}$ oxidase to generate superoxide anions. The light emissions produced by the reactions between lucigenin $(5 \mu \mathrm{M})$ and the superoxide anions were measured with a luminometer $(20 / 20 n$, Turner, CA, USA) once every minute for ten minutes. The values represented NAD(P)H oxidase activity and were expressed as mean light unit (MLU) per minute per milligram of protein.

\section{Measurement of superoxide anions}

Lucigenin-derived chemiluminescence was used to determine superoxide anion levels in the PVN, as described in our previous reports [24, 26, 32]. Briefly, the reactions with superoxide anions were started by the addition of dark-adapted lucigenin $(5 \mu \mathrm{M})$ to each tissue sample to induce photon emissions, which were measured with a luminometer (20/20n, Turner, CA, USA) once every minute for ten minutes. The values represented superoxide anion levels and were expressed as a MLU per minute per milligram of protein.

\section{Chemicals}

Ang-(1-7) and A-779 were obtained from Bachem (Bubendorf, Switzerland). Ang II, capsaicin, tempol, diethyldithiocarbamic acid (DETC), apocynin, SQ22536, rp-adenosine-3',5'-cyclic monophosphothionate (Rp-cAMP), dibutyryl-cAMP (db-cAMP), N $\omega$-nitro-l-arginine methyl ester (L-NAME) were purchased from Sigma Chemical Co (St. Louis, MO, USA). Ang-(1-7) and Ang II were made fresh before each experiment. All the chemicals were dissolved in normal saline, with the exception of apocynin, which was dissolved in normal saline containing 1\% dimethyl sulfoxide (DMSO). 


\section{Cellular Physiology Cell Physiol Biochem 2017;42:2523-2539 \begin{tabular}{ll|l} 
and Biochemistry Published online: August 23, 2017 & $\begin{array}{l}\text { (c) } 2017 \text { The Author(s). Published by S. Karger AG, Basel } \\
\text { www.karger.com/cpb }\end{array}$
\end{tabular}

\section{Protocols}

The acute experiments were performed at 6-8 weeks after coronary ligation or sham surgery. Initially, the rats were kept in the supine position. The right carotid artery was cannulated first to detect LV pressure and then to continuously record ABP. Then, endotracheal intubation and sinoaortic denervation and vagotomy were performed. The rats were subsequently kept in a prone position, with their heads fixed in the stereotaxic frame for PVN positioning. The surgery mentioned above was completed in 30-35 min. Finally, the rats were kept in the right lateral position, with their heads fixed in the stereotaxic frame. A left lateral thoracotomy was performed to prepare for the application of chemicals to the epicardium. A left retroperitoneal incision was made, and the renal sympathetic nerve was isolated to place electrodes to record RSNA. The surgery and related operation were completed in another 20-25 min. After these surgeries, the rats were allowed to stabilize for $30 \mathrm{~min}$ before undergoing further treatments.

Protocol 1: The effects of PVN microinjections of saline, Ang-(1-7) (0.03 nmol), A-779 (3 nmol), A-779+Ang-(1-7), Ang II (0.03 nmol) and Ang-(1-7)+Ang II on baseline RSNA and MAP, as well as on the CSAR, were determined in 6 groups of Sham rats and 6 groups of CHF rats ( $n=6$ for each group). The change in RSNA was expressed as the percent change from the value recorded before PVN microinjection. Baseline MAP and RSNA changes reached their maximum at the 8th min after Ang-(1-7) or A-779 microinjection or at the 3rd min after Ang II microinjection. At the time point at which the greatest response to Ang-(1-7), A-779 or Ang II occurred, the CSAR was evaluated by assessing the responses of RSNA and MAP to epicardial capsaicin application. The PVN pretreatment with A-779 or Ang-(1-7) was administered 8 min before Ang(1-7) or Ang II treatment. The doses of treatment with Ang-(1-7), A-799 and Ang II in PVN were decided according to our preliminary studies and previous research reports [18, 19, 33, 34].

Protocol 2: Mas and AT 1 receptor protein expression levels in the PVN, as well as Ang-(1-7) and Ang II levels in the PVN, were determined in 2 groups of Sham rats and 2 groups of CHF rats ( $\mathrm{n}=5$ for each group).

Protocol 3: The effects of PVN microinjections of saline, SQ22536 (2 nmol), db-cAMP (1 nmol) or RpcAMP ( $1 \mathrm{nmol}$ ) on baseline RSNA and MAP and the CSAR, as well as on the responses of RSNA, MAP and the CSAR to Ang-(1-7) (0.03 nmol), were determined in 8 groups of Sham rats and 8 groups of CHF rats ( $n=6$ for each group). The CSAR was evaluated 8 min after PVN microinjection. The PVN pretreatment was administered $8 \mathrm{~min}$ before Ang-(1-7) treatment.

Protocol 4: The effects of PVN microinjections of saline, DETC (10 nmol), tempol (20 nmol), 1\% DMSO, apocynin (APO) (1 nmol) or L-NAME (15 nmol) on baseline RSNA and MAP and the CSAR, as well as on the responses of RSNA, MAP and the CSAR to Ang-(1-7) (0.03 nmol), were determined in 12 groups of Sham rats and 12 groups of CHF rats ( $\mathrm{n}=6$ for each group). CSAR was evaluated $8 \mathrm{~min}$ after PVN microinjection. The PVN pretreatment was administered 8 min before Ang-(1-7) treatment.

Protocol 5: The effects of PVN microinjections of saline, Ang-(1-7) (0.03 nmol), A-779 (3 nmol) and A-779+Ang-(1-7) on cAMP levels, NAD(P)H oxidase activity and superoxide anion levels in the PVN were detected in 4 groups of Sham rats and 4 groups of CHF rats ( $n=5$ for each group). The A-779 pretreatment was administered 8 minutes before Ang-(1-7) treatment. Eight minutes after PVN microinjection, each rat was decapitated and prepared for measurements of cAMP levels, NAD(P)H oxidase activity and superoxide anion levels in the PVN.

Protocol 6. The effects of PVN pretreatment with saline and L-NAME (15 nmol) on the responses of RSNA, MAP and the CSAR to Ang-(1-7) (0.03 nmol) were determined in 2 groups of Sham rats and 2 groups of CHF rats ( $\mathrm{n}=6$ for each group). The CSAR was evaluated 8 min after PVN microinjection. The PVN pretreatment was administered 8 min before Ang-(1-7) treatment.

\section{Statistical analysis}

Data are expressed as the mean \pm S.E. One-way or two-way ANOVA followed by Bonferroni's post-hoc test was used analyze multiple comparisons. $P<0.05$ was considered statistically significant.

\section{Results}

Anatomic and hemodynamic data pertaining to the CHF and Sham rats

BW, heart weights, infarct areas, and baseline hemodynamic parameters were measured at 6-8 weeks after coronary ligation or sham surgery (Table 1). The LV infarct area was 


\section{Cellular Physiology Cell Physiol Biochem 2017;42:2523-2539 \begin{tabular}{ll|l} 
and Biochemistry Published online: August 23, 2017 & $\begin{array}{l}\text { (C) } 2017 \text { The Author(s). Published by S. Karger AG, Basel } \\
\text { www.karger.com/cpb }\end{array}$ \\
\hline
\end{tabular}}

Table 1. Body weight, heart weight, infarcted area and baseline hemodynamics in a representative group of $\mathrm{CHF}$ and Sham rats. $\mathrm{LV}$, left ventricle; $\mathrm{LV}+\mathrm{dP} / \mathrm{dt}$ ${ }_{\max }$ maximum of the first differentiation of $\mathrm{LV}$ pressure. Data are given as mean \pm SE. * $\mathrm{P}<0.05$ compared with Sham rats. $\mathrm{n}=6$ for each group

\begin{tabular}{|c|c|c|}
\hline & Sham & CHF \\
\hline Body weight (g) & $333.7 \pm 4.8$ & $322 \pm 8.9$ \\
\hline Heart weight (g) & $1.3 \pm 0.1$ & $1.6 \pm 0.1 *$ \\
\hline Heart weight/Body weight $(\mathrm{g} / \mathrm{kg})$ & $3.8 \pm 0.1$ & $4.9 \pm 0.2 *$ \\
\hline Infarct size (\% LV area) & 0 & $33.8 \pm 2.2^{*}$ \\
\hline Systolic arterial pressure $(\mathrm{mm} \mathrm{Hg})$ & $128.7 \pm 3.8$ & $105.7 \pm 5.6 *$ \\
\hline Diastolic arterial pressure $(\mathrm{mm} \mathrm{Hg})$ & $75.5 \pm 3.4$ & $73.9 \pm 5.1$ \\
\hline Pulse pressure (mm Hg) & $53.2 \pm 3.1$ & $31.8 \pm 2.6^{*}$ \\
\hline Mean arterial pressure $(\mathrm{mm} \mathrm{Hg})$ & $93.2 \pm 3.2$ & $84.5 \pm 5.2$ \\
\hline Heart rate (beats/min) & $393.9 \pm 7.4$ & $373.8 \pm 11.2$ \\
\hline LV peak systolic pressure $(\mathrm{mm} \mathrm{Hg})$ & $127.4 \pm 4.0$ & $97.4 \pm 6.6 *$ \\
\hline LV end-diastolic pressure $(\mathrm{mm} \mathrm{Hg})$ & $-0.8 \pm 0.6$ & $14.3 \pm 0.8 *$ \\
\hline LV developed pressure (mm Hg) & $128.2 \pm 4.2$ & $83.2 \pm 6.9 *$ \\
\hline $\mathrm{LV}+\mathrm{dP} / \mathrm{dt}_{\max }(\mathrm{mm} \mathrm{Hg} / \mathrm{sec})$ & $3580.6 \pm 83.5$ & $1550.2 \pm 180.9 *$ \\
\hline
\end{tabular}

Table 2. Echocardiographic data of the left ventricle in a representative group of Sham rats and CHF rats. LVEDD, left ventricular end-diastolic diameter; LVESD, left entricular end-systolic diameter; IVSd, interventricular septal thickness in diastole; IVSs, interventricular septal thickness in systole; LVPWd, left ventricular posterior wall thickness in diastole; LVPWs, left ventricular posterior wall thickness in systole; FS, fractional shortening; EF, ejection fraction; LV, left ventricular; BW, body weight. Values are mean \pm SE. $* \mathrm{P}<0.05$ compared with Sham. $\mathrm{n}=6$ for each group

\begin{tabular}{lcc}
\hline & Sham & CHF \\
\hline LVEDD (mm) & $7.12 \pm 0.23$ & $9.56 \pm 0.58^{*}$ \\
LVESD (mm) & $4.65 \pm 0.13$ & $7.08 \pm 0.48^{*}$ \\
IVSd (mm) & $1.79 \pm 0.05$ & $1.83 \pm 0.19$ \\
IVSs (mm) & $2.86 \pm 0.13$ & $2.62 \pm 0.21$ \\
LVPWd (mm) & $1.86 \pm 0.03$ & $1.78 \pm 0.21$ \\
LVPWs (mm) & $3.21 \pm 0.11$ & $2.48 \pm 0.06^{*}$ \\
FS (\%) & $43.4 \pm 1.24$ & $25.9 \pm 0.92^{*}$ \\
EF (\%) & $72.6 \pm 1.33$ & $43.7 \pm 0.98^{*}$ \\
LV mass (g) & $1.19 \pm 0.08$ & $1.51 \pm 0.21^{*}$ \\
LV mass /BW (mg/g) & $3.47 \pm 0.08$ & $4.66 \pm 0.07^{*}$ \\
\hline
\end{tabular}

33.8\% in CHF rats compared to $0 \%$ in Sham rats. The heart weight and heart-to-body weight ratio were significantly increased in CHF rats compared to Sham rats, a finding indicative of the occurrence of compensatory myocardial hypertrophy in the non-infarcted region of the myocardium. Systolic arterial pressure (SAP), pulse pressure (PP), LV peak systolic pressure (LVSP), LV developed pressure (LVDP) and LV $+\mathrm{dp} / \mathrm{dt}_{\max }$ decreased, while LVEDP increased significantly in CHF rats compared to Sham rats. The combination of these hemodynamic data and the abovementioned anatomic data were indicative of the presence of myocardial damage and suggestive of decreased contractile function in CHF rats.

\section{Echocardiography}

Echocardiography was used to evaluate LV function and geometry changes. At 6-8 weeks after coronary artery ligation, LV mass, LV mass/BW, LVEDD and LVESD were significantly enlarged, whereas the LV EF and LV FS were significantly decreased in CHF rats compared to Sham rats (Table 2). These results suggest that CHF rats displayed decreased contractile function and disease manifestations similar to those observed in dilated cardiomyopathy.

\section{Effects of Ang-(1-7) on RSNA, MAP and the CSAR}

The CSAR was enhanced in CHF rats, a finding consistent with those of our previous study [26, 35]. Microinjection of the Ang-(1-7) into PVN significantly increased the baseline RSNA and MAP, peaking at about 8th min and lasting at least $12 \mathrm{~min}$, enhanced the CSAR in both Sham and CHF rats, and these effects were greater in CHF rats than that in Sham rats. 
PVN pretreatment with A-779, a Mas receptor antagonist, abolished the positive effects of Ang-(1-7) on RSNA, MAP and the CSAR. A-779 alone in the PVN decreased the baseline RSNA and MAP, peaking at about 8th min and lasting at least $30 \mathrm{~min}$. Therefore PVN pretreatment with A-779 was administered 8 min before other treatments in this study. A-779 in PVN attenuated the CSAR in both CHF and Sham rats, and the inhibitory effects observed in $\mathrm{CHF}$ rats were much greater than those observed in Sham rats (Fig. 1). There is no significant difference in the period of these effects between Sham and $\mathrm{CHF}$ rats. Representative traces of the effects of PVN microinjections of Ang-(1-7), A779 and A779+Ang-(1-7) on baseline RSNA and MAP, and the CSAR in CHF rats are shown in Fig. 2 and 3.

Effects of Ang-(1-7) on the responses of RSNA, MAP and the CSAR to Ang II

There were no significant differences between Ang-(1-7) and Ang II with respect to the responses of RSNA, MAP and the CSAR. More importantly, PVN pretreatment with Ang-(17) augmented the effects of Ang II on RSNA, MAP and the CSAR in CHF rats. Interestingly, PVN pretreatment with Ang-(1-7) did not enhance the effects of Ang II on the above parameters in Sham rats (Fig. 4).

Mas receptor and $A T_{1}$ receptor protein expressions in the PVN

Both Mas receptor and $\mathrm{AT}_{1}$ receptor protein expressions in the PVN were much higher in CHF rats than in Sham rats (Fig. 5).

Ang-(1-7) and Ang II levels in the PVN

Both Ang-(1-7) and Ang II levels in the PVN were increased in CHF rats compared to Sham rats (Fig. 5).

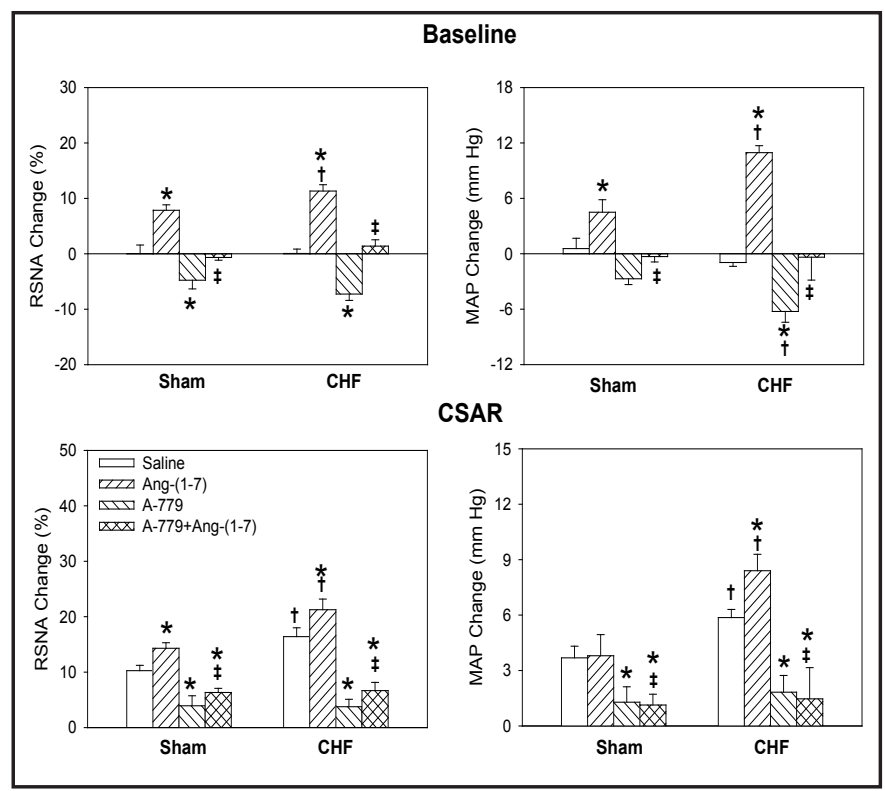

Fig. 1. Effects of PVN microinjection of saline, Ang-(1-7) $(0.03$ nmol), A-779 (3 nmol), A-779+Ang-(1-7) on the baseline RSNA and MAP and CSAR in Sham rats and CHF rats. The CSAR was evaluated by the RSNA and MAP response to epicardial application of capsaicin $(1 \mathrm{nmol})$. Values are mean $\pm \mathrm{SE}$. ${ }^{*} \mathrm{P}<0.05$ compared with saline. $\dagger \mathrm{P}<0.05$ compared with Sham. $\neq \mathrm{P}<0.05$ compared with Ang-(1-7) alone. $n=6$ for each group.

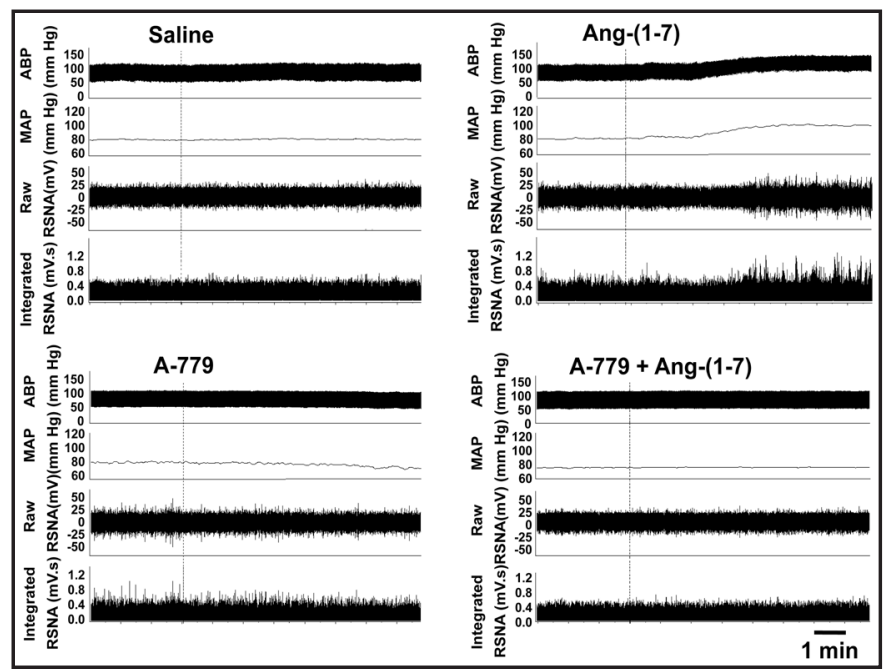

Fig. 2. Representative recordings showing the effects of PVN microinjection of saline, Ang-(1-7) (0.03 nmol), A-779 (3 nmol) and A-779+Ang-(1-7) on the basline RSNA and MAP in CHF rats. 
Fig. 3. Representative recordings showing the effects of PVN microinjection of saline, Ang-(1-7) (0.03 $\mathrm{nmol}), \mathrm{A}-779(3 \mathrm{nmol})$ and A-779+Ang-(1-7) on the CSAR in CHF rats. The CSAR was evaluated by the RSNA and MAP responses to epicardial application of capsaicin $(1 \mathrm{nmol})$.

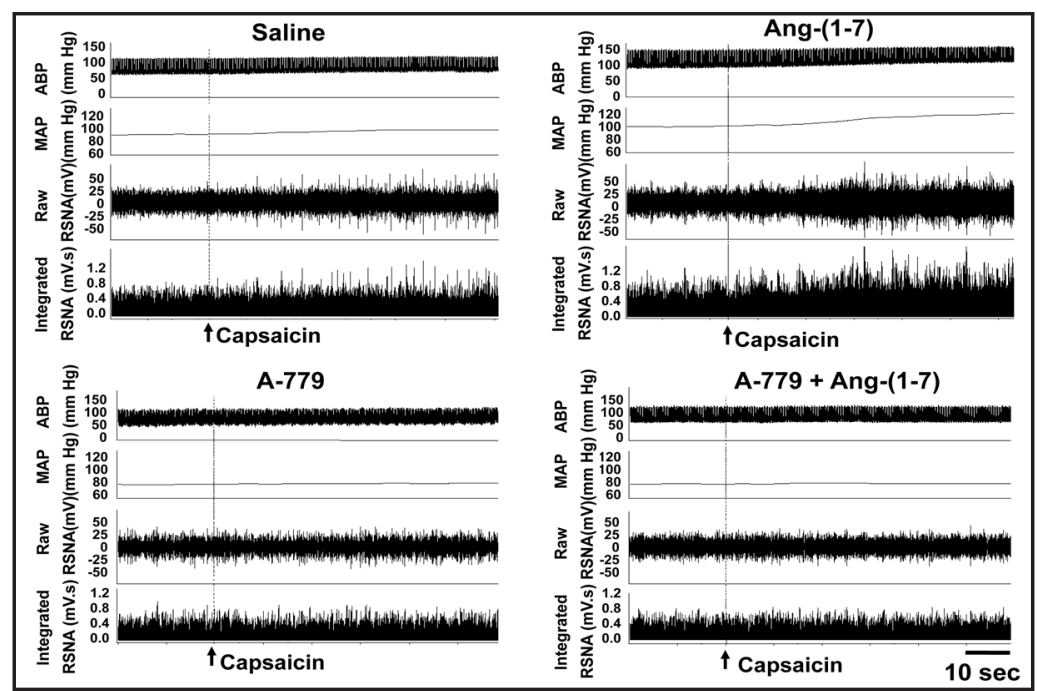

Fig. 4. Effects of PVN microinjection of saline, Ang-(17) $(0.03 \mathrm{nmol})$, Ang II $(0.03$ nmol), Ang-(1-7)+Ang II on the baseline RSNA and MAP and CSAR in Sham rats and CHF rats. The CSAR was evaluated by the RSNA and MAP response to epicardial application of capsaicin (1 nmol). Values are mean \pm SE. $* \mathrm{P}<0.05$ compared with saline. $\dagger$ $\mathrm{P}<0.05$ compared with Sham. \# $\mathrm{P}<0.05$ compared with Ang II alone. $\mathrm{n}=6$ for each group.

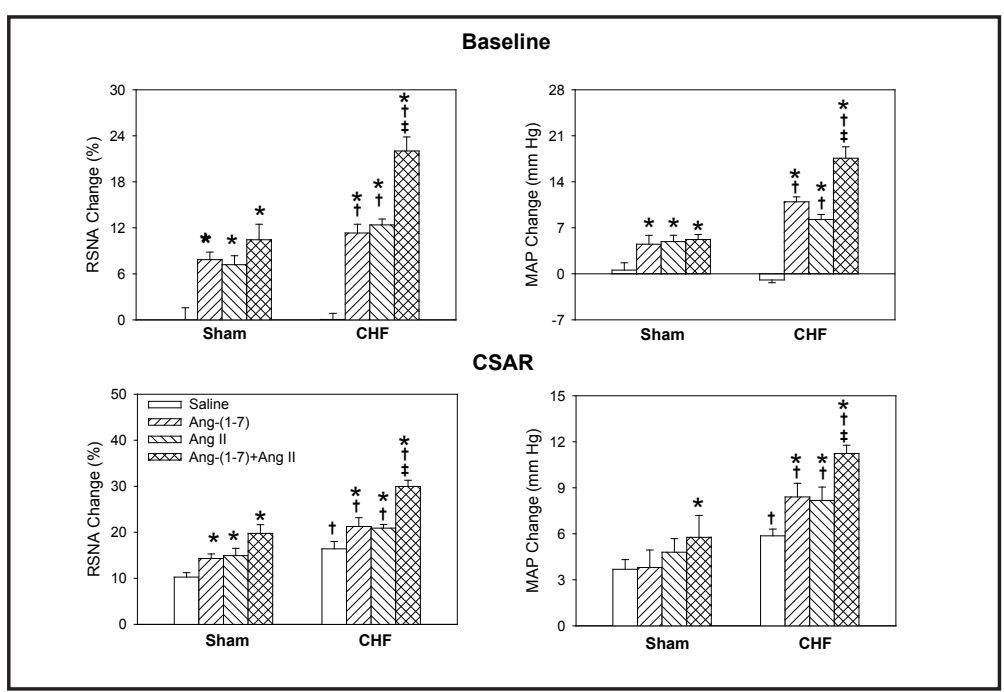

\section{Effects of SQ22536, Rp-cAMP and db-cAMP}

PVN pretreatment with either the AC inhibitor SQ22536 or the PKA inhibitor Rp-cAMP abolished the elevation-inducing effects of Ang-(1-7) on RSNA, MAP and the CSAR in both Sham and CHF rats, while PVN pretreatment with db-cAMP, a cAMP analogue, failed to augment the effects of Ang-(1-7) (Fig. 6). PVN microinjections of SQ22536 or Rp-cAMP alone attenuated the CSAR in both Sham and CHF rats. In addition, SQ22536 decreased baseline RSNA and MAP in CHF rats, but not in Sham rats. Db-cAMP caused greater increases in RSNA and MAP and greater enhancement of the CSAR in CHF rats than in Sham rats (Fig. 7).

\section{Effects of tempol, DETC and apocynin}

PVN pretreatment with the superoxide anion scavenger tempol or the NAD(P)H oxidase inhibitor apocynin markedly attenuated the effects of Ang-(1-7) on RSNA, MAP and the CSAR in both Sham and CHF rats, while DETC, an SOD inhibitor, had no potentiating effects when combined with Ang-(1-7) (Fig. 8). PVN microinjections of either tempol or apocynin alone decreased baseline RSNA and MAP while also inhibiting the CSAR in both sham and CHF rats, while PVN microinjections of DETC increased baseline RSNA and MAP as well as enhancing the CSAR. The magnitude of the response to each of these agents was more pronounced in CHF rats as compared with Sham rats (Fig. 9). 
Fig. 5. Mas receptor protein expression (A), $\mathrm{AT}_{1}$ receptor protein expression (B), Ang-(1-7) level (C) and Ang II level (D) in PVN in Sham rats and CHF rats. Values are mean \pm SE. $* \mathrm{P}<0.05$ compared with Sham rats. $\mathrm{n}=5$ for each group.
Fig. 6. Effects of the PVN pretreatment with saline, SQ22536 ( 2 nmol), db-cAMP (1 nmol) and Rp-cAMP (1 nmol) on the RSNA, MAP and CSAR responses to Ang(1-7) $(0.03 \mathrm{nmol})$ in Sham and CHF rats. The CSAR was evaluated by the RSNA and MAP response to epicardial application of capsaicin (1 nmol). Values are mean $\pm \mathrm{SE} . * \mathrm{P}<0.05$ compared with saline. $\uparrow \mathrm{P}<0.05$ compared with Sham. $n=6$ for each group.
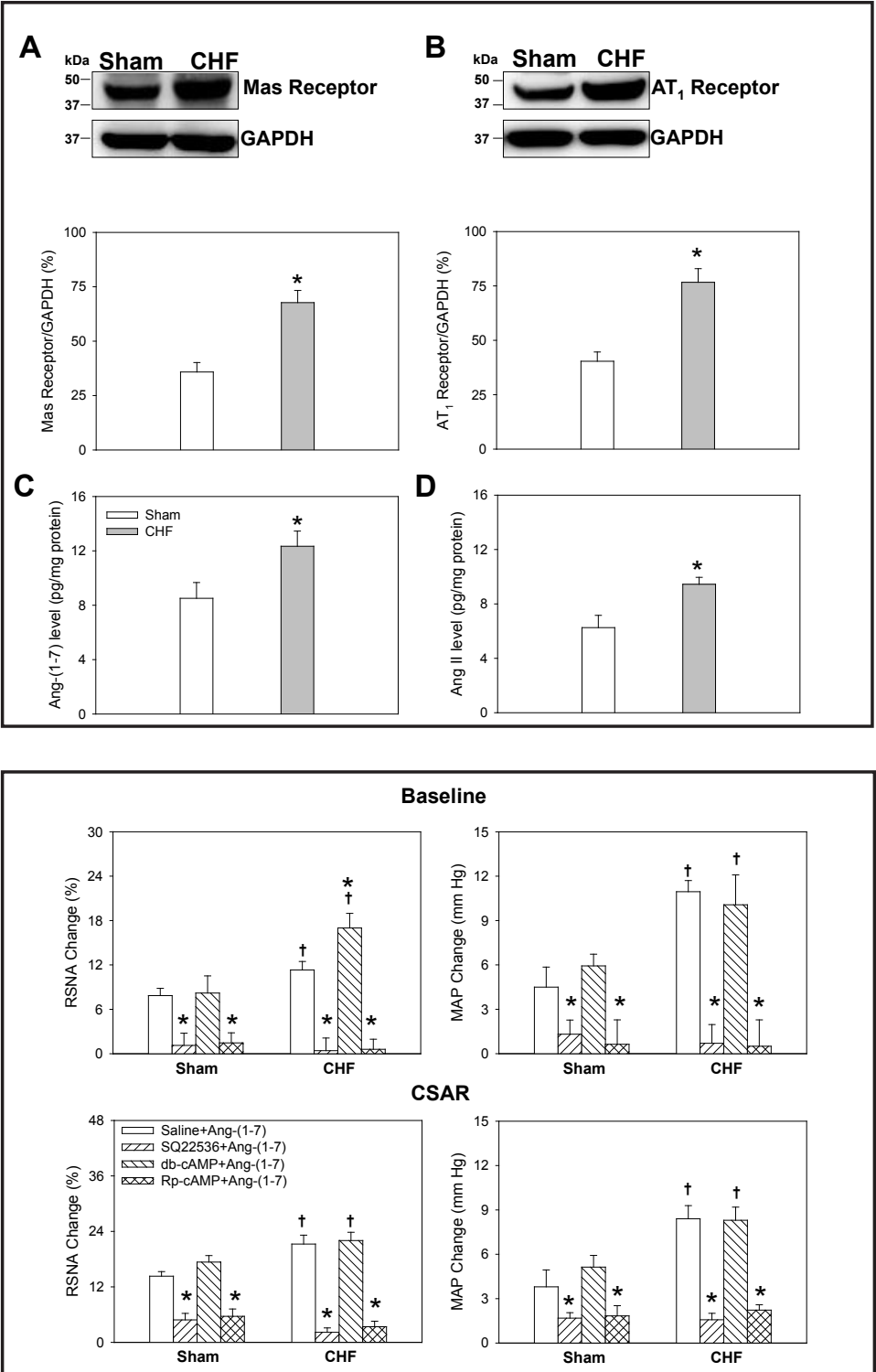

Fig. 7. Effects of the PVN microinjection of saline, SQ22536 (2 nmol), db-cAMP (1 $\mathrm{nmol}$ ) and Rp-cAMP (1 nmol) on the baseline RSNA and MAP and CSAR in Sham and CHF rats. The CSAR was evaluated by the RSNA and MAP response to epicardial application of capsaicin (1 nmol). Values are mean \pm SE. $* \mathrm{P}<0.05$ compared with saline. $+\mathrm{P}<0.05$ compared with Sham. $n=6$ for each group.

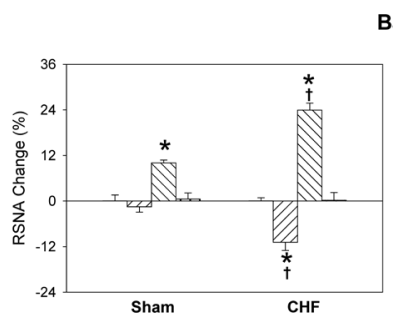

Baseline

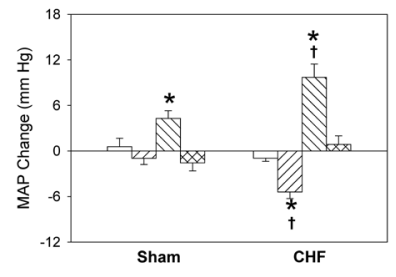

CSAR
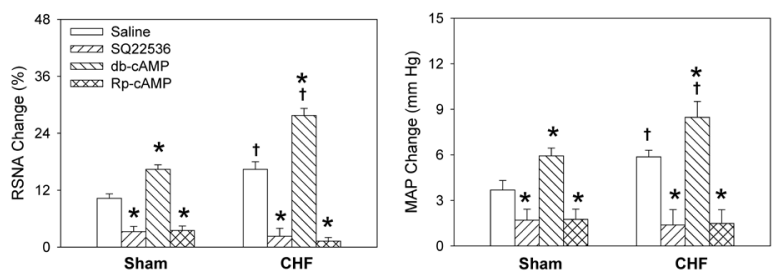
Fig. 8. Effects of the PVN pretreatment with saline, DETC (10 nmol), tempol (20 nmol), $1 \%$ DMSO or apocynin (APO) (1 nmol) on the RSNA, MAP and CSAR responses to Ang-(1-7) $(0.03 \mathrm{nmol})$ in Sham rats and CHF rats. The CSAR was evaluated by the RSNA and MAP response to epicardial application of capsaicin $(1 \mathrm{nmol})$. Values are mean $\pm \mathrm{SE}$. ${ }^{*} \mathrm{P}<0.05$ compared with saline or DMSO. $\uparrow \mathrm{P}<0.05$ compared with Sham. $n=6$ for each group.

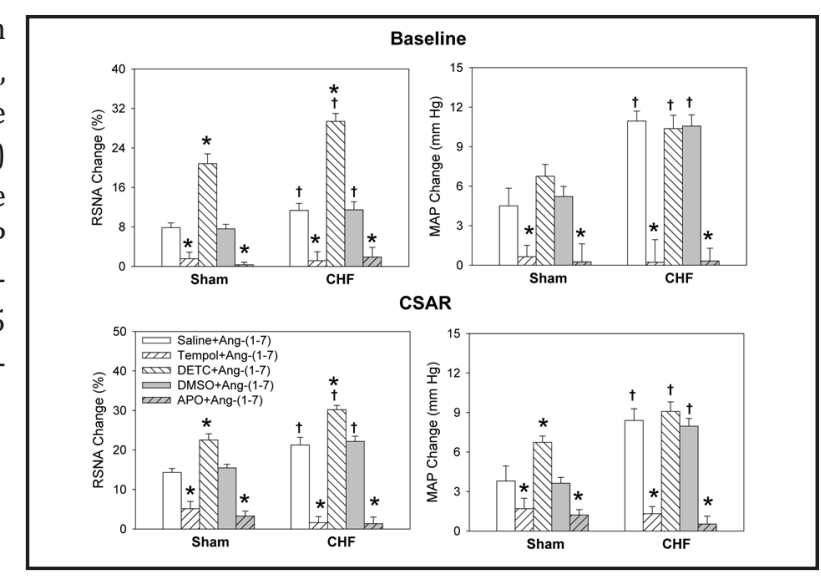

Fig. 9. Effects of the PVN microinjection of saline, DETC (10 nmol), tempol (20 nmol), $1 \%$ DMSO or apocynin (APO) (1 nmol) on the RSNA, MAP and CSAR in Sham rats and CHF rats. The CSAR was evaluated by the RSNA and MAP response to epicardial application of capsaicin (1 nmol). Values are mean \pm SE. * $\mathrm{P}<0.05$ compared with saline or DMSO. $\dagger$ $\mathrm{P}<0.05$ compared with Sham. $\mathrm{n}=6$ for each group.

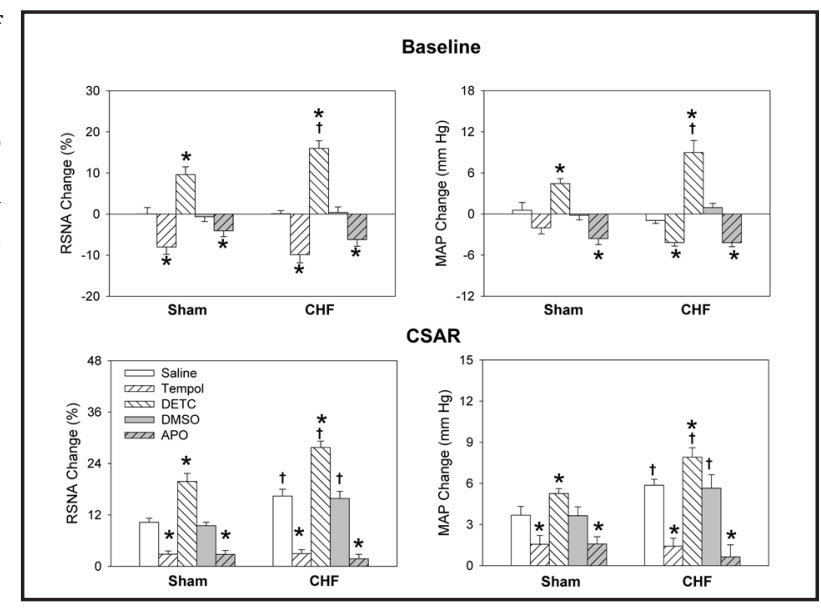

Fig. 10. Effects of the PVN microinjection of saline, Ang-(1-7) (0.03 nmol) , A-779 (3 nmol) and A-779+Ang-(1-7) on the cAMP level, NAD(P)H oxidase activity and superoxide anions level in PVN in Sham and CHF rats. Values are mean \pm SE. $* P<0.05$ compared with Saline. $\dagger \mathrm{P}<0.05$ compared with Sham. $\neq \mathrm{P}<0.05$ compared with Ang-(1-7). $n=5$ for each group.

cAMP levels, NAD $(P) H$ oxidase activity and superoxide anion levels in the PVN

There were no significant differences baseline cAMP levels in PVN between the CHF group and the Sham group. Ang-(1-7) caused greater increases in cAMP levels in PVN in CHF rats than in Sham rats, but A-779 had no significant effect on cAMP levels in either CHF or Sham rats. PVN pretreatment with A-779 blocked the abovementioned Ang-(1-7)-induced increases in cAMP levels (Fig. 10A). $\mathrm{NAD}(\mathrm{P}) \mathrm{H}$ oxidase activity and superoxide anion levels in the PVN in CHF rats increased compared to those in Sham rats. PVN microinjection of Ang-(1-7) increased NAD(P)H oxidase activity and superoxide anion levels within PVN in both CHF and Sham animals, an effect that was more pronounced in CHF rats. A-779 decreased basal NAD(P)

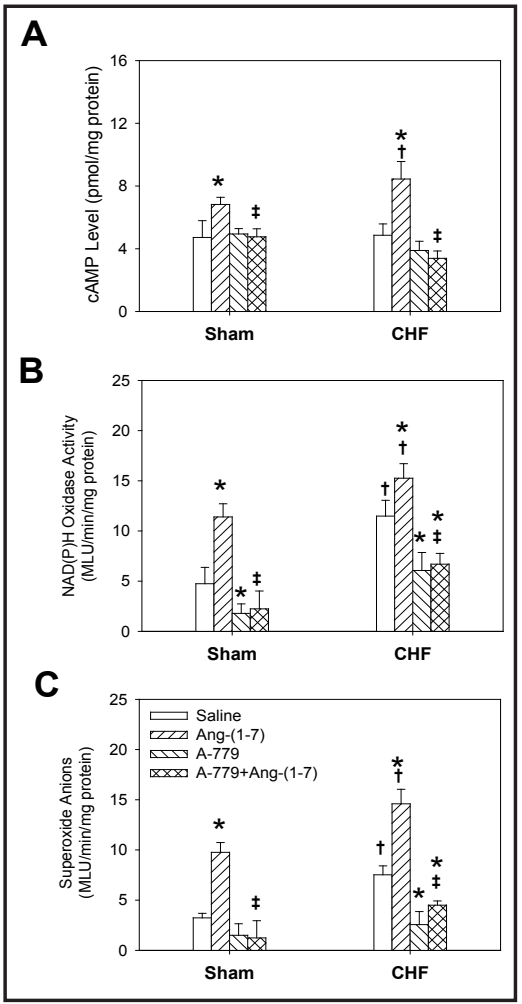


Table 3. Influence of pretreatment with saline or L-NAME on the effects of Ang-(1-7) in the PVN in Sham and CHF rats. The CSAR was evaluated by the RSNA and MAP responses to the epicardial application of capsaicin. Values are expressed as mean $\pm \mathrm{SE}$. ${ }^{*} \mathrm{P}<0.05$ vs. the Saline, $\dagger \mathrm{P}<0.05$ vs. Sham. $\mathrm{n}=6$ for each group

\begin{tabular}{llcccc}
\hline \multirow{2}{*}{ Pretreatment } & \multicolumn{2}{c}{ Sham } & \multicolumn{2}{c}{ CHF } \\
& & Saline & L-NAME & Saline & L-NAME \\
\cline { 2 - 6 } Baseline & RSNA change (\%) & $7.85 \pm 0.98$ & $8.04 \pm 0.99$ & $11.34 \pm 0.74 \dagger$ & $11.77 \pm 0.81 \dagger$ \\
& MAP change (mm Hg) & $4.5 \pm 1.35$ & $5.2 \pm 0.85$ & $11.0 \pm 0.75 \dagger$ & $10.2 \pm 0.99 \dagger$ \\
\multirow{2}{*}{ CSAR } & RSNA change (\%) & $14.31 \pm 1.01$ & $14.85 \pm 1.11$ & $21.26 \pm 1.92 \dagger$ & $20.05 \pm 0.94 \dagger$ \\
& MAP change $(\mathrm{mm} \mathrm{Hg})$ & $3.8 \pm 1.14$ & $4.2 \pm 0.97$ & $8.4 \pm 0.89 \dagger$ & $8.9 \pm 0.85 \dagger$ \\
\hline
\end{tabular}

$\mathrm{H}$ oxidase activity in both $\mathrm{CHF}$ and Sham rats, while superoxide anion level was significantly decreased in only the PVN from CHF rats, with a trend toward lower levels in sham animals. The effects of Ang-(1-7) in the PVN, with respect to NAD(P)H oxidase activity and superoxide anion level, were blocked by PVN pretreatment with A-779 (Fig. 10B \& C).

\section{Effects of L-NAME}

PVN pretreatment with L-NAME, a nitric oxide (NO) synthase inhibitor, had no significant influence on Ang-(1-7)-induced RSNA, MAP and CSAR elevations in either Sham or CHF rats (Table 3).

\section{Discussion}

The findings of previous studies from our laboratory indicate that the CSAR is enhanced and contributes to sympathetic activation in CHF rats. PVN Ang II/AT 1 receptor activity plays a crucial role in enhancing the CSAR and inducing excessive sympathetic activation in CHF. The findings of the present study show that Mas receptor activation by Ang-(1-7) in the PVN increases sympathetic output and enhances the CSAR in CHF rats at least in part through a ROS dependent cAMP-PKA pathway activation. Furthermore, Ang-(1-7) in the PVN enhances the effects of Ang II in CHF rats. Endogenous Ang-(1-7) and Mas receptor activity contribute to CSAR enhancement and excessive sympathetic activation in CHF rats.

It is well known that Ang II is an important biologically active peptide from the RAS family which is effected by some factors such as exercise [36, 37]. The discovery of Ang(1-7) within the last decade added a new important component to the RAS family. Dense Mas receptor and $\mathrm{AT}_{1}$ receptor expression occur in the PVN $[13,14,19,36]$. Mas receptors in particular, have been shown to have unique and specific activity in response to Ang-(17) which is distinct from either Ang II or the angiotensin receptors, $\mathrm{AT}_{1}$ and $\mathrm{AT}_{2}$. Central Ang-(1-7) has also been found to play important roles in regulating sympathetic outflow and cardiovascular activity $[38,39]$. Previous studies have shown that Ang II in the PVN enhances the CSAR and sympathetic output by activating the $\mathrm{AT}_{1}$ receptor and contributes to the pathogenesis of CSAR enhancement in CHF [26, 40-42]. Some studies have reported that the Ang-(1-7)/Mas receptor axis plays hypotensive or sympathoinhibitory roles in some peripheral tissues and some parts of the brain [43-45], and opposes the effects of Ang II,

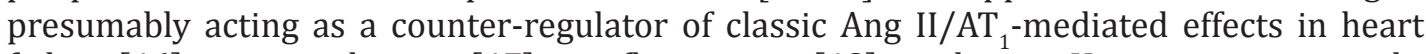
failure [46], emotional stress [47] or inflammatory [48] conditions. However, interestingly, previous studies have also shown that this heptapeptide in the PVN uncovered an unusual role in the maintenance of sympathetic nerve activity. Indeed, microinjection of Ang-(17) into the PVN increases RSNA which can be blocked by its selective antagonist, A-779, indicating that this compound has an excitatory action on PVN neurons [34]. Numerous studies also have found that Ang-(1-7) plays a similar and possibly complimentary role to Ang II at various central sites, both mirroring the Ang II response and augmenting the effects of Ang II on cardiovascular activities [33, 49-52]. The findings of our recent studies indicate that microinjections of Ang-(1-7) into either the PVN or the RVLM increase RSNA 
and MAP and enhance the CSAR $[17,18]$. Moreover, Ang-(1-7) augments the effects of Ang II in renovascular hypertensive rats $[19,20]$. All of these reports above suggest that the overall effects of Ang-(1-7) on sympathetic nerve activity and blood pressure control are complex. Ang-(1-7) appears to have unique effects based on the central nervus system (CNS) area involved and, potentially, the experimental disease model utilitzed. In the present study, we found that the CSAR was enhanced in CHF rats, a finding consistent with those of our previous study [26] and that exogenous Ang-(1-7) administration in PVN increased RSNA and MAP and enhanced the CSAR to a greater extent in CHF rats than in Sham rats. The effects of Ang(1-7) in the PVN are similar to the effects of Ang II, a consequence that is attributed to Mas receptor activation given that selective antagonism of this receptor with A-779 abrogated these effects. In addition, Ang-(1-7) in PVN potentiates the effects of Ang II on the CSAR, blood pressure and sympathetic outflow in CHF rats. These findings indicated that Ang-(1-7) enhances the CSAR and sympathetic output not only by exerting its own effects but also by enhancing the effects of Ang II in the CHF state, effects similar to those exerted by Ang-(17) in renovascular hypertension. These effects were facilitated by Mas receptor activation. We also found that treatment of the PVN with A-779 alone significantly decreased baseline RSNA and MAP, and attenuated the CSAR to a greater extent in CHF rats than in Sham rats, indicating that there is a basal level of Ang-(1-7)/Mas receptor activity within the PVN that is more pronounced in CHF rats which contributes to CSAR enhancement and sympathetic activation in CHF rats and can be targeted to reduce both systemic blood pressure and renal sympathetic activity. The findings of the current study suggest that Ang-(1-7) in PVN may play an unusual or special role in regulating sympathetic outflow and blood pressure in CHF, a role that differs from its broader and well-established roles, which put forward a new and different cognition for the therapeutic potential of Ang-(1-7) for heart failure, as suggested in a previous report [46].

In the current study, we found that both Ang-(1-7) levels and Mas receptor protein expression in the PVN in CHF rats were increased compared with those in Sham rats, findings similar to those regarding the Ang II/AT 1 receptor, indicating that the enhanced effects of Ang-(1-7) in the PVN in CHF rats are probably the results of both Mas receptor expression upregulation and Ang-(1-7) level elevations. Both overexcited Ang-(1-7)/Mas receptor activity and Ang II/AT ${ }_{1}$ receptor activity contribute to CSAR enhancement and sympathetic activity potentiation in the CHF state. Ang-(1-7)/Mas receptor activity seems to play a more important role in this process than Ang II/AT 1 receptor activity; thus, suppressing Ang-(17)/Mas receptor activity may slow the development and progression of the CHF state.

Our previous work identified that the cAMP-PKA pathway is involved in the excitatory effects of Ang-(1-7) on sympathetic activity, blood pressure and the CSAR in the PVN and RVLM; blockade of the cAMP-PKA pathway in the PVN or RVLM attenuates increased sympathetic activity induced by Ang-(1-7) in renovascular hypertension [17, 18]. Similarly, we were interested in this pathway for Ang-(1-7) mediated changes in the PVN from animals with CHF. It has been known that Ang-(1-7) elevates cAMP concentrations in primary cells, such as endothelial or mesangial cells. PKA inhibitors block the effect of Ang-(1-7) on the Ang II-stimulated proximal tubule $\mathrm{Na}^{+}$-ATPase, while cAMP mimics the effects of Ang-(1-7); Ang-(1-7) upregulates ATP-binding cassette transporter A1 expression through the cAMP signaling pathway in RAW 264.7 macrophages [22, 53-55]. In present study, reducing the production of cAMP, by using a specific membrane-permeable AC inhibitor, or blocking PKA activity, by a specific membrane-permeable PKA inhibitor, attenuated Ang-(1-7)-induced RSNA and MAP elevations and CSAR enhancement in both CHF and Sham rats. Microinjections of Ang-(1-7) into the PVN caused a greater increase in cAMP levels in CHF rats than in Sham rats. These effects were abolished by pretreatment with the Mas receptor antagonist A779. These results indicate that the cAMP-PKA pathway is involved in regulating the effects of Ang-(1-7) on RSNA, MAP and the CSAR in CHF rats. In addition, we also found that SQ22536 alone in the PVN decreased baseline RSNA and MAP in CHF rats, and that both SQ22536 and Rp-cAMP significantly attenuated the CSAR in both CHF and Sham rats, while db-cAMP, a cAMP analogue, caused greater increases in RSNA and MAP and greater enhancement of the 
CSAR in CHF rats than in Sham rats, which suggests that the cAMP-PKA pathway contributes to tonic control of the CSAR and sympathetic activation in CHF.

It has been reported that NAD(P)H oxidase-derived ROS in the PVN are novel molecules that contribute to the enhancement of the CSAR in CHF rats $[26,56,57]$ and are involved in the brain intracellular signaling pathways of Ang II [31, 58, 59]. The results of our previous study showed that NAD (P)H oxidase-derived superoxide anions in the RVLM also play roles in modulating the effects of Ang-(1-7) on RSNA and MAP and the CSAR in normal rats [25]. However, whether ROS are the intracellular signals that regulate the effects of Ang-(1-7) in the PVN in CHF rats remains unclear. In the present study, scavenging free radicals or inhibiting NAD(P)H oxidase inhibitor within the PVN abolished the effects of exogenous Ang(1-7) on RSNA, MAP and CSAR in both CHF and Sham rats. By preventing the catalyzation of ROS species, using microinjection of a SOD inhibitor into the PVN, we show augmented RSNA, MAP and CSAR both in the presence and absence of exogenous Ang-(1-7). Again, the effects for each of these agents were more pronounced in CHF animals and even in the absence of Ang-(1-7) stimulation there was a prominent effect. NAD(P)H oxidase activity and superoxide anion levels were increased in CHF rats compared with Sham rats, and microinjections of Ang-(1-7) into the PVN caused additional increases in these levels, while A-779 treatment decreased NAD(P)H oxidase activity and superoxide anion levels to a greater extent in CHF rats than in Sham rats. Moreover, the effects of Ang-(1-7) were abolished by pretreatment with A779. These results suggested that the abovementioned NAD(P)H oxidase-derived superoxide anions in the PVN are important intracellular signaling molecules that mediate the positive effects of Ang-(1-7) on RSNA, MAP and the CSAR in CHF rats.

In the present study, we found that both the cAMP-PKA pathway and NAD(P)H oxidasederived superoxide anions in the PVN are involved in mediating the effects of Ang-(1-7) on RSNA, MAP and the CSAR in CHF rats. These findings led us to question whether a relationship exists between these two intracellular signaling pathways, given that they mediate the effects of Ang-(1-7) together. Some studies have reported that a complicated relationship exists between the AC-cAMP-PKA signaling pathway and ROS production [60,61]. Depletion of NAD(P)H oxidase 4 expression by siRNA decreased arginine vasopressin-inducible cellular cAMP concentrations, PKA activity and aquaporin-2 mRNA expression induced by forskolin, a potent activator of $\mathrm{AC}$, in mpkCCDcl4 cells [61]. Therefore, we speculated that the effects of Ang-(1-7) in the PVN in CHF rats is through Mas receptor activation followed by ROSmediated activation of AC-cAMP-PKA pathway, a phenomenon that needs to be studied in the future.

It has been reported that NO mediates some effects of Ang-(1-7) via Mas receptors in some tissues $[52,62]$. To determine whether $\mathrm{NO}$ is involved in mediating the effects of Ang(1-7) on RSNA, MAP and the CSAR in CHF rats, we examined the influence of the NO synthase inhibitor L-NAME on the effects of Ang-(1-7). We found that L-NAME had no significant influence on Ang-(1-7)-induced increases in RSNA and MAP and enhancements of the CSAR in either Sham or CHF rats, which suggested that inhibiting NO synthase to decrease the NO generation had no effect on Ang-(1-7)-induced increases in RSNA and MAP or enhancement of the CSAR. NO is not involved in the sympatho-excitatory and CSAR-enhancing effects of Ang-(1-7) in the PVN in CHF.

In the present study, we found that Ang-(1-7) played roles similar to those of Ang II, moreover, Ang-(1-7) potentiated the effects of Ang II on the CSAR, blood pressure and sympathetic outflow in CHF rats. It is known that both $\mathrm{AT}_{1}$ receptors and Mas receptors are selective G protein-coupled receptors [16]. Furthermore, NAD(P)H oxidase-derived superoxide anions and cAMP-PKA signaling pathways implicated in the present study have also been shown to be important to the effects of Ang II [31, 59, 63]. Therefore, we speculate that Ang II and Ang-(1-7) participate in similar intracellular downstream signaling pathways in the PVN in CHF, which may explain the similarities in the effects exerted by these two agents and the abovementioned Ang-(1-7)-mediated enhancements of the effects of Ang II. 


\section{Cellular Physiology Cell Physiol Biochem 2017;42:2523-2539 \begin{tabular}{l|l|l} 
and Biochemistry Published onlıne: August 23, 2017 & $\begin{array}{l}\text { (c) } 2017 \text { The Author(s). Published by S. Karger AG, Basel } \\
\text { www.karger.com/cpb }\end{array}$
\end{tabular}

\section{Conclusion}

Ang-(1-7) in the PVN enhances the CSAR and sympathetic output in CHF rats not only by exerting its own effects but also by enhancing the effects of Ang II through Mas receptor activation, an effect that is further augmented in CHF rats. Endogenous Ang-(1-7) in the PVN contributes to CSAR enhancement and sympathetic activation in CHF. Both NAD(P)H oxidasederived superoxide anions and the cAMP-PKA signaling pathway are important intracellular signaling mechanisms that mediate the positive effects of Ang-(1-7) on RSNA, MAP and the CSAR in CHF rats. Interventions targeting the Ang-(1-7)/Mas receptor activity in the PVN may be developed as therapeutic strategies for treating this cardiovascular diseases, CHF.

\section{Abbreviations}

CHF (chronic heart failure); Ang-(1-7) (angiotensin-(1-7)); PVN (paraventricular nucleus); CSAR (cardiac sympathetic afferent reflex); RSNA (renal sympathetic nerve activity); ABP (arterial blood pressure); MAP (mean arterial pressure); LV (left ventricle); A-779 (D-Alanine-Ang-(1-7)); ACE (angiotensin converting enzyme); Ang II (angiotensin II); $\mathrm{AT}_{1}$ (angiotensin type 1); SOD (superoxide dismutase); ROS (reactive oxygen species); PKA (protein kinase A); NO (nitric oxide);

\section{Acknowledgements}

The authors express their sincere thanks to the Collaborative Innovation Center for Cardiovascular Disease Translational Medicine for its generous support. This work was supported by the National Natural Science Foundation of China [81470538] and the Jiangsu Provincial Natural Science Foundation of China [BK20131391].

\section{Disclosure Statement}

The authors declare no conflicts of interest.

\section{References}

1 Urrutia J, Alday A, Gallego M, Malagueta-Vieira LL, Arechiga-Figueroa IA, Casis O, Sanchez-Chapula JA: Mechanisms of IhERG/IKr Modulation by alpha1-Adrenoceptors in HEK293 Cells and Cardiac Myocytes. Cell Physiol Biochem 2016;40:1261-1273.

-2 Cohn JN, Levine TB, Olivari MT, Garberg V, Lura D, Francis GS, Simon AB, Rector T: Plasma norepinephrine as a guide to prognosis in patients with chronic congestive heart failure. N Engl J Med 1984;311:819-823.

-3 Zhu GQ, Zucker IH, Wang W: Central AT1 receptors are involved in the enhanced cardiac sympathetic afferent reflex in rats with chronic heart failure. Basic Res Cardiol 2002;97:320-326.

4 Wang HJ, Wang W, Cornish KG, Rozanski GJ, Zucker IH: Cardiac sympathetic afferent denervation attenuates cardiac remodeling and improves cardiovascular dysfunction in rats with heart failure. Hypertension 2014;64:745-755.

5 Grassi G, Seravalle G, Quarti-Trevano F, Dell'oro R: Sympathetic activation in congestive heart failure: evidence, consequences and therapeutic implications. Curr Vasc Pharmacol 2009;7:137-145.

6 Gan XB, Duan YC, Xiong XQ Li P, Cui BP, Gao XY, Zhu GQ: Inhibition of cardiac sympathetic afferent reflex and sympathetic activity by baroreceptor and vagal afferent inputs in chronic heart failure. PLoS One 2011;6:e25784.

7 Floras JS: Sympathetic nervous system activation in human heart failure: clinical implications of an updated model. J Am Coll Cardiol 2009;54:375-385. 


\section{Cellular Physiology Cell Physiol Biochem 2017;42:2523-2539 \begin{tabular}{l|l|l} 
and Biochemistry Published online: August 23, 2017 & $\begin{array}{l}\text { (c) } 2017 \text { The Author(s). Published by S. Karger AG, Basel } \\
\text { www.karger.com/cpb }\end{array}$
\end{tabular}

8 Ferguson DW, Berg WJ, Sanders JS: Clinical and hemodynamic correlates of sympathetic nerve activity in normal humans and patients with heart failure: evidence from direct microneurographic recordings. J Am Coll Cardiol 1990;16:1125-1134.

-9 Li DP, Pan HL: Glutamatergic inputs in the hypothalamic paraventricular nucleus maintain sympathetic vasomotor tone in hypertension. Hypertension 2007;49:916-925.

10 Zhong MK, Duan YC, Chen AD, Xu B, Gao XY, De W, Zhu GQ: Paraventricular nucleus is involved in the central pathway of cardiac sympathetic afferent reflex in rats. Exp Physiol 2008;93:746-753.

11 Esteban V, Heringer-Walther S, Sterner-Kock A, de Bruin R, van den Engel S, Wang Y, Mezzano S, Egido J, Schultheiss HP, Ruiz-Ortega M, Walther T: Angiotensin-(1-7) and the g protein-coupled receptor MAS are key players in renal inflammation. PLoS One 2009;4:e5406.

12 Gironacci MM, Adamo HP, Corradi G, Santos RA, Ortiz P, Carretero OA: Angiotensin (1-7) induces MAS receptor internalization. Hypertension 2011;58:176-181.

13 Krob HA, Vinsant SL, Ferrario CM, Friedman DP: Angiotensin-(1-7) immunoreactivity in the hypothalamus of the (mRen-2d)27 transgenic rat. Brain Res 1998;798:36-45.

14 Becker LK, Etelvino GM, Walther T, Santos RA, Campagnole-Santos MJ: Immunofluorescence localization of the receptor Mas in cardiovascular-related areas of the rat brain. Am J Physiol Heart Circ Physiol 2007;293:H1416-1424.

15 Santos RA, Campagnole-Santos MJ, Baracho NC, Fontes MA, Silva LC, Neves LA, Oliveira DR, Caligiorne SM, Rodrigues AR, Gropen Junior C, et al.: Characterization of a new angiotensin antagonist selective for angiotensin-(1-7): evidence that the actions of angiotensin-(1-7) are mediated by specific angiotensin receptors. Brain Res Bull 1994;35:293-298.

-16 Santos RA, Haibara AS, Campagnole-Santos MJ, Simoes e Silva AC, Paula RD, Pinheiro SV, Leite MF, Lemos VS, Silva DM, Guerra MT, Khosla MC: Characterization of a new selective antagonist for angiotensin-(1-7), D-pro7-angiotensin-(1-7). Hypertension 2003;41:737-743.

17 Han Y, Sun HJ, Li P, Gao Q Zhou YB, Zhang F, Gao XY, Zhu GQ: Angiotensin-(1-7) in paraventricular nucleus modulates sympathetic activity and cardiac sympathetic afferent reflex in renovascular hypertensive rats. PLoS One 2012;7:e48966.

18 Li P, Sun HJ, Cui BP, Zhou YB, Han Y: Angiotensin-(1-7) in the rostral ventrolateral medulla modulates enhanced cardiac sympathetic afferent reflex and sympathetic activation in renovascular hypertensive rats. Hypertension 2013;61:820-827.

19 Sun HJ, Li P, Chen WW, Xiong XQ Han Y: Angiotensin II and angiotensin-(1-7) in paraventricular nucleus modulate cardiac sympathetic afferent reflex in renovascular hypertensive rats. PLoS One 2012;7:e52557.

20 Li P, Zhang F, Sun HJ, Zhang F, Han Y: Angiotensin-(1-7) enhances the effects of angiotensin II on the cardiac sympathetic afferent reflex and sympathetic activity in rostral ventrolateral medulla in renovascular hypertensive rats. J Am Soc Hypertens 2015;9:865-877.

-21 Krishnan B, Torti FM, Gallagher PE, Tallant EA: Angiotensin-(1-7) reduces proliferation and angiogenesis of human prostate cancer xenografts with a decrease in angiogenic factors and an increase in sFlt- 1 . Prostate 2013;73:60-70.

-22 Liu GC, Oudit GY, Fang F, Zhou J, Scholey JW: Angiotensin-(1-7)-induced activation of ERK1/2 is cAMP/ protein kinase A-dependent in glomerular mesangial cells. Am J Physiol Renal Physiol 2012;302:F784-790.

23 Han Y, Zhang Y, Wang HJ, Gao XY, Wang W, Zhu GQ: Reactive oxygen species in paraventricular nucleus modulates cardiac sympathetic afferent reflex in rats. Brain Res 2005;1058:82-90.

24 Han Y, Yuan N, Zhang SJ, Gao J, Shi Z, Zhou YB, Gao XY, Zhu GQ: c-Src in paraventricular nucleus modulates sympathetic activity and cardiac sympathetic afferent reflex in renovascular hypertensive rats. Pflugers Arch 2011;461:437-446.

25 Li P, Zhang F, Zhou YB, Cui BP, Han Y: Superoxide anions modulate the effects of angiotensin-(1-7) in the rostral ventrolateral medulla on cardiac sympathetic afferent reflex and sympathetic activity in rats. Neuroscience 2012;223:388-398.

26 Han Y, Shi Z, Zhang F, Yu Y, Zhong MK, Gao XY, Wang W, Zhu GQ: Reactive oxygen species in the paraventricular nucleus mediate the cardiac sympathetic afferent reflex in chronic heart failure rats. Eur J Heart Fail 2007;9:967-973.

27 Cao X, Sun Z, Zhang B, Li X, Xia H: The Effects of Ivabradine on Cardiac Function after Myocardial Infarction are Weaker in Diabetic Rats. Cell Physiol Biochem 2016;39:2055-2064. 


\section{Cellular Physiology Cell Physiol Biochem 2017;42:2523-2539 \begin{tabular}{l|l|l} 
and Biochemistry Published onlıne: August 23, 2017 & $\begin{array}{l}\text { (c) } 2017 \text { The Author(s). Published by S. Karger AG, Basel } \\
\text { www.karger.com/cpb }\end{array}$
\end{tabular}

28 Xing J, Li J: Bradykinin Contributes to Sympathetic and Pressor Responses Evoked by Activation of Skeletal Muscle Afferents P2X in Heart Failure. Cell Physiol Biochem 2016;39:2101-2109.

-29 Han Y, Fan ZD, Yuan N, Xie GQ Gao J, De W, Gao XY, Zhu GQ: Superoxide anions in the paraventricular nucleus mediate the enhanced cardiac sympathetic afferent reflex and sympathetic activity in renovascular hypertensive rats. J Appl Physiol (1985) 2011;110:646-652.

30 Caruso C, Carniglia L, Durand D, Gonzalez PV, Scimonelli TN, Lasaga M: Melanocortin 4 receptor activation induces brain-derived neurotrophic factor expression in rat astrocytes through cyclic AMP-protein kinase A pathway. Mol Cell Endocrinol 2012;348:47-54.

31 Zhang Y, Yu Y, Zhang F, Zhong MK, Shi Z, Gao XY, Wang W, Zhu GQ: NAD(P)H oxidase in paraventricular nucleus contributes to the effect of angiotensin II on cardiac sympathetic afferent reflex. Brain Res 2006;1082:132-141.

-32 Sun HJ, Zhao MX, Ren XS, Liu TY, Chen Q, Li YH, Kang YM, Wang JJ, Zhu GQ: Salusin-beta Promotes Vascular Smooth Muscle Cell Migration and Intimal Hyperplasia After Vascular Injury via ROS/NFkappaB/MMP-9 Pathway. Antioxid Redox Signal 2016;24:1045-1057.

33 Zhou LM, Shi Z, Gao J, Han Y, Yuan N, Gao XY, Zhu GQ: Angiotensin-(1-7) and angiotension II in the rostral ventrolateral medulla modulate the cardiac sympathetic afferent reflex and sympathetic activity in rats. Pflugers Arch 2010;459:681-688.

-34 Silva AQ Santos RA, Fontes MA: Blockade of endogenous angiotensin-(1-7) in the hypothalamic paraventricular nucleus reduces renal sympathetic tone. Hypertension 2005;46:341-348.

-35 Shi Z, Chen AD, Xu Y, Chen Q, Gao XY, Wang W, Zhu GQ: Long-term administration of tempol attenuates postinfarct ventricular dysfunction and sympathetic activity in rats. Pflugers Arch 2009;458:247-257.

-36 Allen AM, Zhuo J, Mendelsohn FA: Localization and function of angiotensin AT1 receptors. Am J Hypertens 2000;13:31S-38S.

-37 Marchon C, de Marco Ornelas E, da Silva Viegas KA, Lacchini S, de Souza RR, Fonseca FL, Maifrino LB: Effects of moderate exercise on the biochemical, physiological, morphological and functional parameters of the aorta in the presence of estrogen deprivation and dyslipidemia: an experimental model. Cell Physiol Biochem 2015;35:397-405.

-38 Velez JC, Ryan KJ, Harbeson CE, Bland AM, Budisavljevic MN, Arthur JM, Fitzgibbon WR, Raymond JR, Janech MG: Angiotensin I is largely converted to angiotensin (1-7) and angiotensin (2-10) by isolated rat glomeruli. Hypertension 2009;53:790-797.

-39 Gomes da Silva AQ Xavier CH, Campagnole-Santos MJ, Caligiorne SM, Baltatu OC, Bader M, Santos RA, Fontes MA: Cardiovascular responses evoked by activation or blockade of GABA(A) receptors in the hypothalamic PVN are attenuated in transgenic rats with low brain angiotensinogen. Brain Res 2012;1448:101-110.

40 Zhu GQ, Gao L, Patel KP, Zucker IH, Wang W: ANG II in the paraventricular nucleus potentiates the cardiac sympathetic afferent reflex in rats with heart failure. J Appl Physiol (1985) 2004;97:1746-1754.

41 Zhu GQ, Gao L, Li Y, Patel KP, Zucker IH, Wang W: AT1 receptor mRNA antisense normalizes enhanced cardiac sympathetic afferent reflex in rats with chronic heart failure. Am J Physiol Heart Circ Physiol 2004;287:H1828-1835.

-42 Wang HJ, Zhang F, Zhang Y, Gao XY, Wang W, Zhu GQ: AT1 receptor in paraventricular nucleus mediates the enhanced cardiac sympathetic afferent reflex in rats with chronic heart failure. Auton Neurosci 2005;121:56-63.

-43 Mendoza A, Lazartigues E: The compensatory renin-angiotensin system in the central regulation of arterial pressure: new avenues and new challenges. Ther Adv Cardiovasc Dis 2015;9:201-208.

44 Xia H, Sriramula S, Chhabra KH, Lazartigues E: Brain angiotensin-converting enzyme type 2 shedding contributes to the development of neurogenic hypertension. Circ Res 2013;113:1087-1096.

45 Xu P, Sriramula S, Lazartigues E: ACE2/ANG-(1-7)/Mas pathway in the brain: the axis of good. Am J Physiol Regul Integr Comp Physiol 2011;300:R804-817.

46 Patel VB, Zhong JC, Grant MB, Oudit GY: Role of the ACE2/Angiotensin 1-7 Axis of the Renin-Angiotensin System in Heart Failure. Circ Res 2016;118:1313-1326.

47 Fontes MA, Martins Lima A, Santos RA: Brain angiotensin-(1-7)/Mas axis: A new target to reduce the cardiovascular risk to emotional stress. Neuropeptides 2016;56:9-17.

48 Gaddam RR, Chambers S, Bhatia M: ACE and ACE2 in inflammation: a tale of two enzymes. Inflamm Allergy Drug Targets 2014;13:224-234. 


\section{Cellular Physiology Cell Physiol Biochem 2017;42:2523-2539 \begin{tabular}{l|l} 
DOI: 10.1159/000480214 23, 2017 & $\begin{array}{l}\text { O 2017 The Author(s). Published by S. Karger AG, Basel } \\
\text { www.karger.com/cpb }\end{array}$ \\
\hline
\end{tabular} \\ Ren et al.: Ang-(1-7) in Chronic Heart Failure}

49 Nie W, Yan H, Li S, Zhang Y, Yu F, Zhu W, Fan F, Zhu J: Angiotensin-(1-7) enhances angiotensin II induced phosphorylation of ERK1/2 in mouse bone marrow-derived dendritic cells. Mol Immunol 2009;46:355361.

50 Du D, Chen J, Liu M, Zhu M, Jing H, Fang J, Shen L, Zhu D, Yu J, Wang J: The effects of angiotensin II and angiotensin-(1-7) in the rostral ventrolateral medulla of rats on stress-induced hypertension. PLoS One 2013;8:e70976.

51 Nakagaki T, Hirooka Y, Ito K, Kishi T, Hoka S, Sunagawa K: Role of angiotensin-(1-7) in rostral ventrolateral medulla in blood pressure regulation via sympathetic nerve activity in Wistar-Kyoto and spontaneous hypertensive rats. Clin Exp Hypertens 2011;33:223-230.

52 Zimmerman MC: Angiotensin II and angiotensin-1-7 redox signaling in the central nervous system. Curr Opin Pharmacol 2011;11:138-143.

53 Tetzner A, Gebolys K, Meinert C, Klein S, Uhlich A, Trebicka J, Villacanas O, Walther T: G-Protein-Coupled Receptor MrgD Is a Receptor for Angiotensin-(1-7) Involving Adenylyl Cyclase, cAMP, and Phosphokinase A. Hypertension 2016;68:185-194.

54 Liang B, Wang X, Yan F, Bian YF, Liu M, Bai R, Yang HY, Zhang NN, Yang ZM, Xiao CS: Angiotensin-(1-7) upregulates (ATP-binding cassette transporter A1) ABCA1 expression through cyclic AMP signaling pathway in RAW 264.7 macrophages. Eur Rev Med Pharmacol Sci 2014;18:985-991.

55 Lara LS, Vives D, Correa JS, Cardozo FP, Marques-Fernades MF, Lopes AG, Caruso-Neves C: PKA-mediated effect of MAS receptor in counteracting angiotensin II-stimulated renal Na+-ATPase. Arch Biochem Biophys 2010;496:117-122.

56 Yu Y, Zhong MK, Li J, Sun XL, Xie GQ, Wang W, Zhu GQ: Endogenous hydrogen peroxide in paraventricular nucleus mediating cardiac sympathetic afferent reflex and regulating sympathetic activity. Pflugers Arch 2007;454:551-557.

57 Gao L, Wang W, Li YL, Schultz HD, Liu D, Cornish KG, Zucker IH: Superoxide mediates sympathoexcitation in heart failure: roles of angiotensin II and NAD(P)H oxidase. Circ Res 2004;95:937-944.

58 Zimmerman MC, Davisson RL: Redox signaling in central neural regulation of cardiovascular function. Prog Biophys Mol Biol 2004;84:125-149.

-59 Griendling KK, Ushio-Fukai M: Reactive oxygen species as mediators of angiotensin II signaling. Regul Pept 2000;91:21-27.

60 Chini CC, Grande JP, Chini EN, Dousa TP: Compartmentalization of cAMP signaling in mesangial cells by phosphodiesterase isozymes PDE3 and PDE4. Regulation of superoxidation and mitogenesis. J Biol Chem 1997;272:9854-9859.

61 Feraille E, Dizin E, Roth I, Derouette JP, Szanto I, Martin PY, de Seigneux S, Hasler U: NADPH oxidase 4 deficiency reduces aquaporin-2 mRNA expression in cultured renal collecting duct principal cells via increased PDE3 and PDE4 activity. PLoS One 2014; 9:e87239.

-62 Yang RF, Yin JX, Li YL, Zimmerman MC, Schultz HD: Angiotensin-(1-7) increases neuronal potassium current via a nitric oxide-dependent mechanism. Am J Physiol Cell Physiol 2011;300:C58-64.

-63 Nakamura A, Johns EJ, Imaizumi A, Niimi R, Yanagawa Y, Kohsaka T: Role of angiotensin II-induced cAMP in mesangial TNF-alpha production. Cytokine 2002;19:47-51. 